\title{
AS MÚLTIPLAS LEITURAS DA METÁFORA NO TEXTO LITERÁRIO: UMA CONTRIBUIÇÃO PARA A FORMAÇÃO DO LEITOR PROTAGONISTA E REFLEXIVO
}

Ariane Mieco Sugayama

\begin{abstract}
RESUMO
Em busca de uma formação do leitor literário mais protagonista e reflexivo, este artigo analisa as múltiplas leituras da metáfora do poema "Rosa", de Cecília Meireles, geradas na prática de leitura dialógica e colaborativa Pensar Alto em Grupo, no que se refere à coconstrução e à negociação dos sentidos. Pretende-se, ainda, investigar de que maneira as metáforas conceptuais participaram do processo de compreensão das metáforas poéticas.
\end{abstract}

PALAVRAS-CHAVE: letramento literário; Pensar Alto em Grupo; metáfora.

\section{Introdução}

1

de extrema urgência refletirmos sobre os problemas presentes no ensino de literatura, assim como propormos novas práticas que possam estar mais afinadas com a finalidade de um letramento literário comprometido com a formação protagonista e reflexiva do leitor. Entretanto, o que ainda encontramos em sala de aula é um tipo de prática de leitura escolar dominante que silencia a voz interpretativa do leitor empírico e sua subjetividade. Dessa maneira, a fim de contribuir para uma mudança paradigmática no ensino-aprendizagem de leitura - da leitura única às múltiplas leituras -, este artigo analisa os dados gerados em uma prática de letramento dialógica e colaborativa, intitulada Pensar Alto em Grupo (ZANOTTO, 1995; 2014a; 2014b), no que se refere: 1. à 
coconstrução e negociação dos sentidos da metáfora, no poema "Rosa", de Cecília Meireles; 2. a compreender de que maneira as metáforas conceptuais (LAKOFF \& JONHSON, 2002) participaram do processo de compreensão das metáforas poéticas no texto literário (LAKOFF \& TURNER, 1989).

\section{A prática de leitura escolar dominante e a espistemologia do monologismo}

A prática de leitura escolar dominante ${ }^{1}$, cujos pressupostos são orientados por uma epistemologia monológica da linguagem, está fortemente arraigada no contexto escolar, o que nos levou a uma concepção de ensino-aprendizagem que valida apenas uma leitura, geralmente, a do material didático, endossada pela voz do professor enquanto autoridade interpretativa do texto.

Marková (1997), em Language and a epistemology of dialogism, procurou apresentar duas epistemologias que regem as humanidades e os estudos sociais: a monológica e a dialógica. A epistemologia monológica, em linhas gerais, concebe os objetos de conhecimento como entidades discretas, preferencialmente de uma maneira objetiva e de um ponto de vista neutro do observador que as relaciona, agrupando-as em categorias que fazem parte de sistemas maiores com uma organização hierárquica. Bakhtin e Volochinov (2010, p. 112) denominaram essa orientação filosófico-linguística de objetivismo abstrato, criticando o modo como é concebida a língua: "Na base dos fundamentos teóricos do objetivismo abstrato, estão as premissas de uma visão do mundo racionalista e mecanicista, as menos favoráveis a uma concepção correta da história; ora, a língua é um fenômeno puramente histórico". No que se refere ao ensino de leitura, o monologismo orienta modos específicos de refletir, agir e ler, presentes na prática de leitura escolar dominante, levando os alunos a comportamentos de passividade e alienação de suas vozes, pois ler é apenas decodificar, memorizar, copiar e parafrasear o que "está" no texto e é "passado" pelo professor. De acordo com Kleiman (2002, p.23), nesse tipo de

1 É importante ressaltar que a prática de leitura escolar dominante não possui uma teoria implícita (MIZUKAMI, 1986), assim como se atualiza a partir de um habitus, termo cunhado e conceptualizado por Bourdieu, sendo, portanto, um tipo de história corporificada internalizada e assim esquecida como história (BAYNHAM; PRINSLOO, 2009, p.7), ou seja, nós a carregamos, mas não temos consciência dela. 
prática, está integrada uma concepção autoritária de leitura que parte do princípio de que há apenas uma maneira de ler: "[...] a análise de elementos discretos seria o caminho para se chegar a uma leitura autorizada, a contribuição do aluno e sua experiência é dispensável, e a leitura torna-se avaliação do grau de proximidade ou distância entre a leitura do aluno e a interpretação 'autorizada”'. As vozes em sala de aula são abafadas e compartimentadas, pois os alunos ficam enredados ao monólogo do educador, não podendo se expressar nem interagir com os colegas, pois o professor "será sempre o que sabe, enquanto os educandos serão sempre os que não sabem. A rigidez destas posiçóes nega a educação e o conhecimento como processos de busca” (FREIRE, 1987, p.58). Portanto, há pouco espaço para a construção de novos sentidos e pontos de vista embasados no conhecimento de mundo dos alunos e descobertas sobre o que se leu. Ao se enfatizar apenas uma leitura como a correta, os leitores que não se adequarem à solução dada pelo professor e/ou material didático - que assumem o papel de autoridade interpretativa do texto - podem ser criticados. A fim de propor novas maneiras de atuar no ensino de leitura literária, permitindo, sobretudo, a reflexão colaborativa e o exercício do protagonismo do sujeito, a prática de letramento Pensar Alto em Grupo vem sendo construída, paulatinamente, a partir de uma epistemologia do dialogismo, que nos leva ao desafio de lidar com as múltiplas leituras em sala aula. A próxima seção explicitará tais aspectos.

\section{Pensar alto em grupo e a epistemologia do dialogismo}

O Pensar Alto em Grupo é uma prática de letramento que vem sendo construída pelo grupo de pesquisa GEIM (Grupo de Estudos da Indeterminação e da Metáfora). Os participantes do grupo, quando utilizam o Pensar Alto em Grupo, estáo aperfeiçoando e construindo uma prática inovadora que busca transformar a atuação tanto dos alunos quanto dos professores em sala de aula, bem como refletir sobre questóes referentes à leitura e ao letramento. No início, ele era utilizado individualmente (Pensar Alto) (ERICSSON; SIMON, 1984) como um instrumento introspectivo pelos pesquisadores do grupo GEIM, com o intuito de saber como os leitores compreendiam as metáforas presentes no texto. Naquele momento, Zanotto $(1992 ; 1995)$ notou que o Pensar Alto individual gerava dados pouco relevantes, pois os participantes 
ficavam inibidos quando se deparavam com as incongruências geradas pela metáfora, assim como ocorria a expectativa de interpretar o texto corretamente para a professora-pesquisadora. Desse modo, ela precisou repensar essa técnica de pesquisa. Sobre tal mudança, Zanotto (2014a, p. 197) relata:

Assim propus que pensassem em grupo e resolvessem colaborativamente o enigma proposto pelas metáforas. Por essa razão, a técnica passou a se chamar 'Pensar Alto em Grupo' (1992,1995), que logo mostrou resultados melhores para pesquisa e para os participantes, que saíam da vivência com uma imagem mais positiva de si mesmos como leitores.

Como podemos notar, o Pensar Alto em Grupo até este momento era utilizado apenas como um instrumento de geração de dados (MASON, 1996), mas, com o decorrer do tempo, os pesquisadores perceberam seu potencial pedagógico enquanto prática de leitura. A partir desse momento, tornou-se, portanto, segundo Zanotto (2007, p. 102), "uma prática social de leitura, na qual os leitores, numa interação face a face, partilham, negociam, constroem e avaliam os diferentes sentidos (ZANOTTO, 1997, p. 3). Em outras palavras, eles socializam os diferentes sentidos". A realização do Pensar Alto em Grupo ocorre em dois momentos: no primeiro momento, é distribuído o texto a todos os participantes, para que façam uma leitura individual, silenciosa e introspectiva, privilegiando, portanto, a interação dos sujeitos com o autor, mediado pelo texto. Os leitores são também orientados para não se preocuparem com possíveis dificuldades na compreensão de alguma passagem do texto, pois estas poderão ser comentadas no grupo, para que todos possam refletir sobre elas de forma colaborativa; no segundo momento, os participantes têm espaço para suas vozes e subjetividades, a fim de que possam compartilhar suas leituras, sem a preocupação de estarem corretas ou erradas, pois a construção dessas leituras é concebida em termos de hipóteses, que podem ser mais ou menos relevantes em relação ao texto.

Devido ao fato de darmos espaço para a voz e a subjetividade dos leitores, é possível que múltiplas leituras ocorram, pois cada leitor traz seu contexto pessoal e cultural, conhecimentos prévios, crenças, etc. Entretanto, é importante ressaltar que o desafio de lidar com um ensino que considera as múltiplas 
leituras não implica aceitação de tudo o que foi construído, pois o professor, em um processo de negociação de sentidos, deverá pensar alto com o grupo, a fim de se decidir colaborativamente quais leituras são pertinentes, com base em uma noção intuitiva de relevância. Entretanto, para que esse tipo de interação ocorra em sala de aula, é necessário que o professor não dê simplesmente espaço para a voz e subjetividade dos alunos, mas que ele seja capaz de: "saber ouvir, legitimar essa voz, muitas vezes ampliando-a para o grupo (O’Connor \& Michaels, 1996; Vieira, 1999), assim como [...] saber orquestrar as vozes dos participantes, mediar a construção das leituras e possibilitar que os alunos sejam mediadores uns para os outros" (ZANOTTO, 2014a, p. 216). Portanto, ele deixa de lado seu poder de autoridade interpretativa do texto e de professor diretivo, revendo todo o funcionamento da estrutura usual da conversa em sala de aula (PONTECORVO, 2005), para trabalhar com perguntas em menor quantidade e de uma qualidade que possa levar a uma maior expansão das ideias e dos pensamentos dos leitores. Em suma, podemos notar, a partir de toda essa explicitação sobre o histórico e o funcionamento do Pensar Alto em Grupo, que, embora este pareça ser apenas uma simples conversa sobre o texto, o que se tem revelado - nas leituras dos alunos em interface com a ação do professor - são características especiais no modo de ler e atuar em sala de aula, coerentes com os pressupostos da epistemologia do dialogismo.

Segundo Marková (1997), para a epistemologia do dialogismo o ponto de partida do conhecimento não são as entidades discretas, mas o todo relacional, ou seja, os objetos do conhecimento existem apenas na relação com algo e quem procura conhecer toma um ponto de vista particular desses objetos, em vez de examiná-los de maneira objetiva. A compreensão desses objetos é fundamentalmente reflexiva, pois ocorre um ativo envolvimento da consciência humana do eu-outro; dessa forma para Bakhtin (2003), toda compreensão é dialógica. O dialogismo foi estudado, de forma zelosa, pelos filósofos neokantianos que presumivelmente cunharam o termo 'dialogismo', absorvendo muito das ideias de Hegel, com ênfase nas que se referem à consciência do eu, no sentido de que o indivíduo adquire simultaneamente o conceito de si e do outro. Então, Mikhail Bakhtin, ao entrar em contato com o pensamento desses filósofos, provavelmente adotou tal termo para se referir ao pensamento humano e sua presença na obra literária de Dostoiévski (MARKOVÁ, 1997). A partir desse momento, juntamente com o diálogo estabelecido com outras vertentes filo- 
sóficas e áreas do conhecimento que floresciam em sua época (BRAIT, 2007), Bakhtin e os integrantes do Círculo elaboraram um conceito de língua(gem) como um acontecimento linguístico estritamente dialógico, baseado na interação entre os interlocutores. Para Bakhtin e Volochinov (2010, p. 116), "A verdadeira substância da língua não é constituída por um sistema abstrato de formas linguísticas nem pela enunciação monológica isolada, nem pelo ato psicofisiológico de sua produção, mas pelo fenômeno social da interação verbal, realizada através da enunciação ou das enunciaçôes". Ao reconhecermos que é a partir da interação verbal que se fundamenta a realidade da língua(gem), compreendemos, portanto, que ela não existe separada dos sujeitos, mas sim nas suas relações. Nessa perspectiva, texto e leitor não são compreendidos como entidades discretas, mas um todo relacional, no qual a significação "é como uma faísca elétrica que só se produz quando há contato dos dois pólos opostos [...] Só a corrente da comunicação verbal fornece à palavra a luz da significação" (BAKHTIN/VOLOCHINOV, 2010, p. 137). Esse processo de conhecer algo, a leitura de um texto pelo leitor, não é feito de maneira objetiva, pois para compreender algo é necessário posicionar-se de forma ativa e responsiva, isto é, "A cada palavra da enunciação que estamos em processo de compreender, fazemos corresponder uma série de palavras nossas, formando uma réplica. Quanto mais numerosas e substanciais forem, mais profunda e real é a nossa compreensão" (BAKHTIN/VOLOCHINOV, 2010).

Essa, portanto, é a concepçáo de leitura que explica a atividade de interpretar no Pensar Alto em Grupo, que orienta modos específicos de agir e interagir. Assim, tal prática está de acordo com o Modelo de Letramento Ideológico, no que se refere ao empoderamento da identidade leitora do aluno, que passa a ter sua voz fortalecida e reconhecida como legítima no contexto escolar.

\section{Pensar alto em grupo: o ensino de literatura a partir de uma abor- dagem do letramento ideológico}

Street (1984), em sua obra Literacy in theory and practice, utiliza o termo letramento como uma expressão para designar práticas sociais de leitura e escrita, a fim de problematizar as suposiçóes implícitas e explícitas que dominavam o campo dos estudos de letramento, derivadas do Modelo Autônomo de Letramento. Portanto, houve um afastamento dos estudos de abordagem 
pedagógica e psicolinguística dos processos do leitor/escritor individual, em sala de aula, para compreender a leitura e a escrita como processos sociais, ancorados em outros contextos. Sua reivindicação é de que as práticas de letramento e concepçóes de leitura e escrita são dadas pela sociedade, dependentes de seus contextos, nos quais figuram posiçôes ideológicas, de modo a não serem tratadas como "neutras" ou meramente "técnicas". Para esse autor, essas práticas são ensinadas, e o modo como são compartilhadas depende, sobretudo, de uma formação social. Esse modo de compreender a leitura e a escrita está afinado com a concepção de linguagem bakhtiniana que se interessa pela natureza social dos fatos linguísticos, isto é, as enunciações são compreendidas como indissoluvelmente ligadas às estruturas sociais (BRAIT, 2007). Assim, ao assumirmos o caráter ideológico do signo, é possível concebermos a leitura e a escrita como práticas sociais, atravessadas por ideologias embutidas culturalmente, por meio das quais relaçóes de poder são mantidas e desafiadas. Para Street (1993, p. 9 apud MAGALHÁES, 2012, p. 29), a ideologia é "o local de tensão entre a autoridade e o poder, de um lado, e a resistência e a criatividade, do outro". No que se refere ao Pensar Alto em Grupo, a ideologia que se instaura ao dar, acolher e legitimar a voz dos alunos e suas subjetividades é exatamente a de resistir à prática de leitura escolar dominante, de maneira a empoderá-los a partir da construção de identidades mais protagonistas. Podemos dizer que, nesse processo de interação verbal, potencializa-se a compreensão reflexiva em suas diferentes interaçóes do eu com o outro (leitor/autor; leitor/leitor; leitor/professor), pois todos têm a possibilidade de construir leituras, para além das sancionadas pelo material didático. Por essa razão, o professor, mais do que ficar preocupado com a adaptação das vozes de seus alunos ao material didático, deverá estar atento à coerência dos processos construtivos das leituras, que envolvem a realização de raciocínios inferenciais, a presença da interdiscursividade e da polifonia - evocadas por diversas vozes e discursos, presentes ou ausentes numa perspectiva de alteridade -, gerando uma multiplicidade de leituras. Outra contribuição advinda do Pensar Alto em Grupo é colocar em primeiro plano a natureza artística da literatura, isto é, encarar esse tipo de texto como um discurso que procura satisfazer ao mesmo tempo uma expectativa estética e uma exigência intelectual. De acordo com Jouve (2012, p. 91), "entender uma obra de arte é, então, examinar as complexas relaçôes entre o que é 
mostrado e o modo com que se mostra", sendo a interpretação da metáfora um dos maiores desafios interpretativos a ser realizado pelo leitor. Sobre esse assunto, a próxima seção será dedicada.

\section{A metáfora e sua leitura nos textos literários}

Aristóteles foi o pioneiro a estudar questóes referentes à metáfora em suas obras Poética e Retórica, apresentando-a como uma das mais importantes figuras de linguagem. Para o filósofo grego, a metáfora era um recurso de ornamentação do discurso poético e persuasivo. Nesse quadro teórico, ela era compreendida como um desvio semântico da linguagem literal e um simples ornamento, sendo ignorado o seu valor cognitivo. Esse olhar para com a metáfora está presente em um paradigma filosófico objetivista, em que pares de oposição são apresentados de maneira dicotômica: razão versus emoção; literal versus figurado, assim como o que se busca é uma verdade absoluta. Somente a partir da segunda metade do século XX, um novo paradigma científico começou a surgir, ou seja, a dicotomia objetividade (razão)/subjetividade (emoção) foi se enfraquecendo, levando os estudiosos da metáfora a propor um enfoque experiencialista, o qual propóe uma síntese desses pares de opostos, de maneira tal que a metáfora seria aquela que "une razão e imaginação, isto é, uma racionalidade imaginativa, essencial tanto para a ciência como para a literatura" (ZANOTTO et all, 2002, p. 22). Desse modo, ela passou a ser compreendida, segundo Zanotto e Palma (1998: 168), como "[...] uma operação cognitiva fundamental, constitutiva da linguagem e do pensamento”. No livro Metáforas da Vida Cotidiana, Lakoff \& Jonhson (2002) apresentam a ideia de que o pensamento humano é estruturado metaforicamente. Eles concebem uma teoria por meio da qual discutem a natureza das metáforas no sistema conceptual humano, isto é, a metáfora passa a ser vista mais como um fenômeno de pensamento e ação do que puramente linguístico. Para esclarecer esse funcionamento, vejamos como ocorre a conceptualização de AMOR COMO VIAGEM, que se reflete nas seguintes expressões linguísticas (LAKOFF, 1986 apud ZANOTTO, 2002: 24): "Veja a que ponto chegamos. Agora não podemos voltar atrás. Nós estamos numa encruzilhada. Nossa relação não vai chegar a lugar nenhum”. A teoria da metáfora conceptual ainda propõe que as metáforas são culturais, resultantes de mapeamento de domínios, sendo um de origem (no caso, as viagens) e o outro alvo (no caso, o amor). Esse 
mapeamento é estruturado de forma sistemática, ocorrendo correspondências ontológicas entre as entidades dos dois domínios. Exemplo: Os viajantes são os amantes. Para Lakoff \& Turner (1989), a presença das metáforas conceptuais não está apenas na linguagem cotidiana, mas também na poética. Esses autores observam que, por existirem esses conceitos metafóricos no nosso sistema conceptual cotidiano, é possível entendermos os que estão na linguagem poética. Segundo esses autores (1989, p. XI - XII):

Grandes poetas podem nos comunicar, porque eles usam os modos de pensamento que todos nós possuímos. Usando as capacidades que compartilhamos, os poetas podem iluminar nossa experiência, explorar as consequências de nossas crenças, desafiar os modos como nós pensamos e criticar nossas ideologias. Para entender a natureza e o valor da criatividade poética, nos é necessário compreender os modos como nós pensamos cotidianamente ${ }^{2}$.

Dentre essas metáforas que fazem parte do nosso sistema conceptual e que encontramos no texto literário, temos PESSOAS SÃO PLANTAS, isto é, os diversos estágios da vida por que passamos ao longo do tempo - infância, maturidade, velhice e morte - são compreendidos como estágios e partes de uma planta. De acordo com Lakoff \& Turner (1989, p. 6), “[...] pessoas são vistas como plantas em relação ao ciclo da vida - mais precisamente, elas são vistas como aquela parte da planta que floresce e então murcha ou declina, tais como folhas, flores e fruto, embora às vezes a planta toda seja vista como florescendo ou declinando $[\ldots]^{3}$. Outra metáfora conceptual que encontramos na nossa linguagem cotidiana e que está presente nos textos literários é PROPÓSITOS SÃO DESTINOS, isto é, quando nós pensamos a vida como plena

2 No original, em inglês: "Great poets can speak to us because they use the modes of thought we all possess. Using the capacities we all share, poets can illuminate our experience, explore the consequences of our beliefs, challenge the ways we think, and criticize our ideologies. To understand the nature and value of poetic creativity requires us to understand the ordinary ways we think".

3 No original, em inglês: "In this metaphor, people are viewed as plants with respect to the life cycle - more precisely, they are viewed as that part of the plant that burgeons and then withers or declines, such as leaves, flowers, and fruit, though sometimes the whole plant is viewed as burgeoning and the declining [...]". 
de propósitos, nós a conceptualizamos como tendo destinos e caminhos para chegarmos a eles, o que faz da VIDA UMA VIAGEM. Segundo Lakoff \& Turner (1989, p. 3): "Nós descrevemos pessoas como 'fazendo seus caminhos na vida'. Pessoas se preocupam se 'estão chegando a algum lugar' em suas vidas, e sobre 'dar uma direção a suas vidas'. Pessoas que 'sabem aonde elas estão indo na vida’ são geralmente admiradas” ${ }^{\text {‘ }}$. As metáforas presentes no texto literário desafiam o leitor, pois ele tem que lidar com as incongruências semânticas ou pragmáticas (CAMERON, 2003) do texto, levando-o a um conflito intelectual desestabilizador (SCHENEUWLY; DOLZ, 2004 apud ZANOTTO, 2011) que gera uma construção dos sentidos, a partir de mapeamentos metafóricos e diversos tipos de raciocínios inferenciais, extrapolando o que "está" no texto. Para Zanotto (2010), o desafio do leitor de lidar com essas incongruências pode levá-lo à construção de múltiplas leituras, uma vez que a natureza da metáfora é indeterminada, ou seja, ao interagirmos com ela, trazemos nossos próprios sentidos para sua compreensão, o que pode acarretar uma variedade de leituras. Para compreendermos como esses sentidos da metáfora foram construídos no momento da leitura, um desenho metodológico de acordo com as teorias até aqui expostas será apresentado na próxima seção.

\section{Metodologia de pesquisa e de análise}

Este trabalho se insere no paradigma qualitativo (CHIZZOTTI, 2008), pois aborda os fenômenos sócio-histórico-culturais, ou seja, a realidade é compreendida como dinâmica e a subjetividade dos pesquisadores e participantes são consideradas. Dessa maneira, uma vez que abrimos espaço para a voz dos participantes das práticas sociais investigadas, é utilizada uma metodologia de orientação interpretativista (MOITA LOPES, 2006), que considera fundamental ouvi-los. O instrumento de geração de dados é o próprio Pensar Alto em Grupo que era utilizado de forma individual e considerado introspectivo, no seu início, no cognitivismo, mas que, atualmente, passou a ser reinterpretado em uma dimensão social e em grupo. Os dados foram gerados em um Curso de Extensão Universitária, no ano de 2012, no qual ministrei aulas, juntamente

4 No original, em inglês: "We describe people as 'making their way in life'. People worry about whether they 'are getting anywhere' with their lives, and about 'giving their lives some direction'. People who 'know where they're going in life' are generally admired". 
com outras professoras. Os participantes do evento de leitura foram oito alunas que exercem a função de educadoras em diversos níveis de instituições escolares particular e pública. Com relação à metodologia de análise de dados, realizei os seguintes procedimentos: 1 . houve a transcrição da gravação de toda a interação verbal entre os participantes, sendo, portanto, esse momento uma pré-análise dos dados; 2. dividi a transcrição em conteúdos temáticos que contemplavam as metáforas como foco das interpretações dos leitores; 3. houve uma seleção de alguns conteúdos temáticos, constituindo excertos para serem analisados. $\mathrm{O}$ texto-objeto da pesquisa foi o poema "Rosa" ${ }^{5}$ de Cecília Meireles.

\section{Apresentação e discussão de análise de dados}

\section{EXCERTO 1 - Primeira leitura: a Rosa é uma mulher de vida sofrida}

$\begin{array}{lll}\text { Turnos } & \text { Participantes } & \text { Interaçáo } \\ 3 & \text { Professora Marta } & \text { Vocês gostaram do poema? } \\ 4 & \text { Juliana } & \text { Eu gostei... bastante... já conhecia na verdade (risos) }\end{array}$

Juliana, após responder à professora Marta que gostou do poema e que já o conhecia, comentou que esse texto ficava em uma lousa na sala de trabalho, mas que não havia dado a devida atenção a ele.

\begin{tabular}{|c|c|c|}
\hline Turnos & Participantes & Interação \\
\hline 8 & Juliana & $\begin{array}{l}\text { (risos) mas eu nunca parei para refletir sobre ele... } \\
\text { de verdade }\end{array}$ \\
\hline 9 & Professora Marta & Sei \\
\hline 10 & Juliana & $\begin{array}{l}\text { e lendo agora... vendo assim... com olhar } \\
\text { diferenciado do que eu via todos os dias... eu fiquei } \\
\text { com dó... (risos)... eu tive a sensaçáo de que assim } \\
\text { foi algo sofrido... algo de querer desistir... e assim } \\
\text { náo vê outras possibilidades }\end{array}$ \\
\hline
\end{tabular}

5 Vim pela escada de espinhos./(Mais durável esse esforço/que o esplendor.)/Depois de ascensão tão longa,/Qualquer vento, qualquer chuva/Converte-me em queda e pó./Quando se vê a coroa/Que eu trazia, já não sou./Entre espinhos e derrotas,/qual é o meu tempo de flor? (MEIRELES, 2005, p. 54). 


\begin{tabular}{|c|c|c|}
\hline 11 & Professora Marta & É... \\
\hline 12 & Juliana & $\begin{array}{l}\text { Até... só no final... que eu acho que... eu acho que é } \\
\text { uma mulher... ele fala sobre uma mulher e aí só no } \\
\text { final de tudo que ela... que acho assim... no ápice do } \\
\text { desespero ela para e assim e agora... será que acabou }\end{array}$ \\
\hline & Professora Marta & Humhum... \\
\hline 14 & Juliana & Sei lá... acho que dei uma viajada né... \\
\hline & Todos & (risos) \\
\hline & Professora Marta & $\begin{array}{l}\text { Não... Olha... a gente vai viajar muito... Acho que... } \\
\text { é... quando a gente lê um texto a gente tá acostumado } \\
\text { com a leitura única você tem que dar já uma leitura } \\
\text { que seja a correta... A viajada é... são hipóteses que } \\
\text { você/coisas que o texto fez você pensar }\end{array}$ \\
\hline
\end{tabular}

Juliana conhecia o poema, entretanto, não tinha realizado uma leitura reflexiva, como vimos em seu comentário "mas eu nunca parei para refletir sobre ele... de verdade" (turno 8), de modo a reconhecermos o Pensar Alto em Grupo como uma prática que eleva a leitura a um nível de maior compreensão reflexiva, derivada de um posicionamento responsivo ativo do leitor, pois sua voz é valorizada em sala de aula. Nessa prática, o leitor pode expressar seu ponto de vista sobre o texto, o que pode levá-lo a se sentir ainda um pouco inseguro, já que essa maneira de agir não é a usual no contexto escolar, como é possível observarmos no seguinte comentário de Juliana (turno 14), após construir sua leitura: "sei lá... acho que dei uma viajada né". Essa sua fala demonstra o receio de ter construído uma leitura errada, pois estamos acostumados com a concepção do ensino-aprendizagem da leitura única, a qual nos impele a construirmos apenas uma leitura que deva coincidir com a legitimada pelo material didático e/ou professor, para ser a correta - "quando a gente lê um texto a gente tá acostumado com a leitura única... você tem que dar já uma leitura que seja a correta... (turno 16)", como foi comentado pela professora Marta.

Assim, prosseguindo no esclarecimento, a professora disse que em um evento de Pensar Alto em Grupo, a "viajada” é compreendida como construção de hipóteses de leitura, fruto de questões geradas a partir das reflexôes sobre o texto, fazendo, portanto, parte do processo interpretativo - "a viajada é... são hipóteses que vocêlcoisas que o texto fez você pensar (turno 16). Também é inte- 
ressante notar que o receio da aluna de "dar uma viajada" revela a dificuldade que temos de lidar com a imaginação em sala de aula, pois imaginação e racionalidade parecem compor par de opostos, em que um deve ser privilegiado e o outro, aniquilado. Esse tipo de pensamento está fortemente arraigado em nossa cultura ocidental, que, desde os períodos pré-socráticos até os dias atuais, procura privilegiar a razão em oposição à imaginação. Nessa perspectiva do mito do objetivismo, a metáfora foi compreendida apenas como uma figura de linguagem que enganava a mente racional. Entretanto, no século XX, os novos estudos sobre a metáfora procuraram romper com esse maniqueísmo (razão x imaginação), compreendendo a metáfora como um tipo de racionalidade imaginativa (LAKOFF \&JOHNSON, 2002), por meio da qual pensamos sobre nós e o mundo, assim como orientamos nossas açóes a partir dela.

Considerando, portanto, a metáfora como parte do nosso sistema conceptual, é possível observamos sua participação na linguagem cotidiana e sua presença na criação e na compreensão das metáforas poéticas dos textos literários. Vejamos como isso ocorreu na leitura de Juliana do poema "Rosa": "e lendo agora... vendo assim... com olhar diferenciado do que eu via todos os dias... eu fiquei com dó... (risos)... eu tive a sensação de que assim foi algo sofrido... algo de querer desistir.. e assim não vê outras possibilidades" (turno 10). Podemos, nesse comentário, notar que Juliana não está mais interpretando a rosa no domínio fonte (LAKOFF \& JOHNSON, 2002), ou seja, como simplesmente uma flor, pois uma rosa náo sofre nos termos de querer desistir de algo e de não ver outras possibilidades. Além do mais, o que seria esse algo e não ver outras possibilidades? Embora a aluna não mencione, ela parece estar se referindo à vida humana, pois somente pessoas sofrem nesses termos a ponto de querer desistir da vida, não enxergando outras possibilidades para ela. Dessa maneira, ao reconhecer essa característica particular do sofrimento humano no poema - "algo de querer desistir... e assim não vê outras possibilidades" (turno 10) - a ponto de despertar sua empatia - "eu fiquei com dó... (risos)...."(turno 10) -, Juliana chegou a uma leitura metafórica da rosa como uma mulher "eu acho que é uma mulher... ele fala sobre uma mulher"(turno 12). Essa mulher, para Juliana, parece lamentar os percalços de sua vida, despertando sua comoção, já que a leitora reconhece o seu desespero - "que acho assim... no ápice do desespero ela para e assim e agora... será que acabou...” (turno 12). Notamos que o trecho "será que acabou?" (turno 12) refere-se ao verso último do poe- 
ma, no qual a autora deixa um vazio a ser preenchido pelo leitor, a partir de uma pergunta: "Entre espinhos e derrotas,/qual é o meu tempo de flor?", de modo que os "espinhos" (domínio fonte), para Juliana, foram compreendidos como obstáculos e dificuldades que causam sofrimento (domínio alvo) - "eu tive a sensação de que assim foi algo sofrido" (turno 10) -, o qual leva a mulher ao desespero - "no ápice do desespero" (turno 12) -, questionando quando ele acabará - "será que acabou?” (turno 12). Assim, "qual é o meu tempo de flor?” (domínio fonte) corresponderia a "quanto tempo durará esse desespero causado por uma vida tão sofrida?” (domínio alvo), sendo a mulher de vida sofrida (domínio alvo) uma planta com espinhos, isto é, uma rosa (domínio fonte). Posterior às falas de Juliana, Sylvia iniciou sua leitura (turnos 17 a 29), que teve como resultado a compreensão da rosa apenas como uma planta, ou seja, o poema foi compreendido no seu domínio fonte, mas que logo foi retomada a interpretação no domínio alvo por Mariana, como veremos a seguir.

\section{EXCERTO 2 - Segunda leitura: a Rosa é uma pessoa que se questiona quando ela é ela mesma em sua vida}

\begin{tabular}{|c|c|c|}
\hline Turnos & Participantes & Interaçáo \\
\hline 30 & Mariana & Engraçado né... desculpa \\
\hline 31 & Professora Marta & $\begin{array}{l}\text { Não precisa pedir desculpa pra falar... aqui você tem } \\
\text { todo direito }\end{array}$ \\
\hline 32 & Mariana & $\begin{array}{l}\text { Entre espinhos e derrotas qual o meu tempo de flor é... eu } \\
\text { fiquei imaginando uma pessoa que deve ter uma vida } \\
\text { muito sofrida e dura e que em determinados momentos } \\
\text { ela se questiona ela se pergunta... quando eu sou eu } \\
\text { mesma... em quais momentos da minha vida. }\end{array}$ \\
\hline
\end{tabular}

Mariana, assim como Juliana (excerto 1), compreendeu a rosa como uma pessoa - "Entre espinhos e derrotas qual o meu tempo de flor é... eu fiquei imaginando uma pessoa que deve ter uma vida muito sofrida e dura" (turno 32), sendo o "espinho" (domínio fonte) compreendido como sofrimento dessa pessoa (domínio alvo), a partir de um raciocínio metonímico de causa por efeito, pois, ao tocarmos num espinho (a causa), podemos nos machucar 
(consequência), o que nos leva ao sofrimento (efeito) ${ }^{6}$. Já "tempo de flor" foi compreendido a partir de uma inferência metafórica, o que possibilitou Mariana mapear no ciclo de uma planta a floração, em seu domínio fonte, identificando-a com o momento da vida em que uma pessoa é ela mesma, em seu domínio alvo, dizendo: "em determinados momentos ela se questiona ela se pergunta... quando eu sou eu mesma... em quais momentos da minha vida" (turno 32). Embora Lakoff e Turner (1989) tenham dito que quando "alguém está em plena floração" é porque está na maturidade e não tenham mencionado o fato de a pessoa ser ela mesma, podemos compreender essa maturidade como um estágio de exuberância dos potenciais de uma personalidade, revelando que a pessoa vive com plena autonomia e de acordo com seus anseios pessoais. Nessa perspectiva, a leitura realizada por Mariana parece questionar em que momentos essa pessoa consegue ser ela mesma (mais plena e mais autônoma) em sua vida cheia de sofrimentos. Após essa leitura de Mariana, Maria Eduarda construiu uma interpretação diferente para o poema, como veremos.

\section{EXCERTO 3 - Terceira leitura: o percurso da Rosa até atingir sua floração como o percurso de vida de uma pessoa até realizar seus objetivos}

\section{Turnos Participantes Interaçáo}

$34 \quad$ Maria Eduarda

Hoje de manhã eu vim ouvindo uma música que eu não escutava faz tempo né... e uma/e um dos trechos ela fala assim que a gente se torne flor... né...e aí eu... veio assim justamente ao encontro do poema né

36 Profa. Amanda

Sincronicidade

e aí eu fiquei pensando assim que pra mim... parece assim... que a gente... quando a gente tem um objetivo você vai vem pela escada de espinhos... você vai subindo degrau por degrau de pouco a pouco né... aí você chega lá no topo... que você conseguiu...

37 Maria Eduarda aí você tem a coroa né... só que de repente isso acaba... porque você quer outra coisa... você vai procurar outra coisa...e aí de repente o que eu trazia já não sou né... então assim entre espinhos e derrotas qual é o meu tempo de flor... qual o tempo que eu tô satisfeita né... nossa... puxa agora eu consegui né

\footnotetext{
6 Esse raciocínio metonímico de causa por efeito também foi realizado por Juliana (excerto 1)
} para chegar a essa mesma leitura de espinhos como sofrimento. 
Maria Eduarda, primeiramente, contextualizou sua leitura, por meio de um interdiscurso (FIORIN, 2011) realizado com a letra de uma música recém-ouvida - "Hoje de manhã eu vim ouvindo uma música que eu não escutava faz tempo né... e umale um dos trechos ela fala assim que a gente se torne flor... né." (turno 34), ou seja, ocorreu nesse momento um diálogo interdiscursivo de dois textos: um poema e uma música, a partir do reconhecimento de que em ambos os discursos havia uma concepção dos ciclos da vida humana como os ciclos de uma planta, com ênfase no seu estágio de floração. Segundo Fiorin (2011, p.32), "A interdiscursividade é o processo em que se incorporam percursos temáticos e/ou percursos figurativos, temas e/ou figuras de um discurso em outro". Dessa maneira, a leitura de Maria Eduarda, ao estabelecer um interdiscurso entre os dois textos, ganhou lastro para ser desenvolvida e explorada a ideia de que pessoas podem ser plantas em termos metafóricos. Outro aspecto destacado no poema por Maria Eduarda é que a vida tem propósitos - "parece assim... que a gente... quando a gente tem um objetivo você vai vem pela escada de espinhos" (turno 37), ou seja, nossas vidas podem ser compreendidas como uma viagem, por meio da qual traçamos um caminho, para chegarmos aos destinos que são nossos propósitos. Nessa perspectiva interpretativa, "escada de espinhos" (domínio fonte) é o modo pelo qual nos desenvolvemos a partir de nossos esforços (domínio alvo) - “(...) você vai subindo degrau por degrau de pouco a pouco né..." (turno 37) - para chegarmos a um momento da vida - "aí você chega lá no topo... que você conseguiu..." (turno 37) - no qual realizamos nossos objetivos, para então obtermos o reconhecimento (domínio alvo) - "ai você tem a coroa né..." (turno 37). Assim, o sucesso é algo que está acima, o que nos revela a metáfora orientacional BOM É PARA CIMA (LAKOFF \& JOHNSON, 2002, p.63). Além do mais, podemos notar que o sentido de coroa (domínio fonte), para Maria Eduarda, foi guiado por um raciocínio inferencial metonímico de causa por efeito, sendo a causa a chegada ao topo da escada (o objetivo realizado como destino alcançado), tendo como efeito a coroação (o reconhecimento dessa ação). Entretanto, esse momento de conquista e de reconhecimento na vida - a coroação - é apreendido por Maria Eduarda como algo efêmero - "aí você chega lá no topo... que você conseguiu... ai você tem a coroa né... só que de repente isso acaba... por que você quer outra coisa..." (turno 37) -, assim como a efemeridade do estágio de floração da rosa que logo perderá suas pétalas - "e aí de repente o que eu trazia já não 
sou né” (turno 37). Dessa maneira, Maria Eduarda concluiu que “(...) entre espinhos e derrotas qual é o meu tempo de tempo de flor..." (turno 37) no poema seria a duração da satisfação que sentimos em relação à realização dos objetivos atingidos e reconhecidos, ou seja, como ela mesma disse - "qual o tempo que eu tô satisfeita né... nossa... puxa... agora eu consegui né” (turno 37). Mais à frente na discussão, as alunas apontaram, novamente, a ênfase dada pela poeta às dificuldades e sacrifícios na vida e à fragilidade do ser humano no momento de realização de seus potenciais, citando como exemplo a vida de artistas amplamente reconhecidos, como Marilyn Monroe e Amy Winehouse. A partir dessas falas (turno 38 até o 84), a profa. Marta construiu sua leitura, que, assim como a de Maria Eduarda, parece ter reconhecido as metáforas poéticas nesses dois aspectos: as pessoas são plantas e propósitos são destinos, mas que tiveram resultados diferentes.

\section{EXCERTO 4 - Quarta leitura: a Rosa é a autora Cecília Meireles e alunos em busca da conclusão de um curso de Mestrado e/ou Doutorado}

\section{Turnos Participantes Interaçáo}

85 Professora Marta e pó, né... e eu fiquei me perguntando se na vida dela teve algum tempo maior de reconhecimento da obra... e depois menos reconhecimento... foi uma hipótese que me veio à cabeça... eu não fui verificar na história dela... mas eu pensei na vida da gente... também a gente às vezes para conseguir algum objetivo... pensei muito no contexto que eu vivo de pós-graduação, né... um aluno para fazer um mestrado tem uma escada de espinhos 


\begin{tabular}{|c|c|c|}
\hline 86 & Todas & (risos) \\
\hline 07 & Juliana & Longa \\
\hline 88 & Professora Marta & $\begin{array}{l}\text { e... doutorado e...você tem uma defesa.. ótimo vai } \\
\text { tudo bem... é o tempo de esplendor que é bem } \\
\text { fugaz... porque você tem que malhar e batalhar } \\
\text { de novo para conseguir... parece que o tempo de } \\
\text { esplendor da gente é bem curto... }\end{array}$ \\
\hline 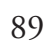 & Juliana & É verdade... passa rápido \\
\hline 9 & Professora Marta & $\begin{array}{l}\text { Cada coisa que vocêalcança você passa por uma escada } \\
\text { de espinhos... você tem que aprender... disciplinar... } \\
\text { trabalhar de forma bastante disciplinada... } \\
\text { responsável e tal e investir dinheiro... tempo, né... } \\
\text { e::: aí você tem aquela glória que é rápida e depois } \\
\text { você tem que continuar a trabalhando muito para } \\
\text { manter o... }\end{array}$ \\
\hline
\end{tabular}

Como podemos notar, para profa. Marta, a rosa foi interpretada como a própria autora do poema, Cecília Meireles - “(...) quando eu li eu pensei na Cecília Meireles no primeiro momento nê" (turno 85). Ou seja, os estágios de vida da poeta foram mapeados, a partir de inferências metafóricas, como ciclos de vida de uma planta. No caso, a planta é uma rosa que é reconhecida por todos pela sua beleza, assim como a poeta Cecília Meireles é reconhecida amplamente pelo público pela beleza de seus poemas; desse modo, "o tempo de flor de esplendor... de reconhecimento da obra... porque também para toda pessoa que expóe, né... se expóe no mundo assim todo artista seja escritor artista atriz de filmes etc... tem um tempo de esplendor e às vezes um tempo de quelde pó, né..." (turno 85). Portanto, tempo de flor (domínio fonte) foi compreendido como o tempo de reconhecimento da obra da poeta (domínio alvo) pelo público, ao mesmo tempo que o declínio da planta, sua queda, até virar pó (domínio fonte) foi compreendido como uma possível época de ostracismo na vida da poeta (domínio alvo). Ainda na esteira dessa reflexão, profa. Marta continuou a desenvolver sua leitura: "e eu fiquei me perguntando se na vida dela teve algum tempo maior de reconhecimento da obra e depois de menos reconhecimento... foi uma hipótese que me veio à cabeça (...)" (turno 85). Logo em seguida, Marta continuou - "mas eu pensei na vida da gente também a 
gente às vezes para conseguir algum objetivo... pensei muito no contexto que eu vivo de pós-graduação, né... um aluno para fazer um mestrado tem uma escada de espinhos" -, ou seja, assim como Maria Eduarda (excerto 3), o sentido de que propósitos na vida são destinos a serem alcançados foi trazido à tona em sua fala. Entretanto, professora Marta, nesse segundo momento da leitura, contextualizou essa metáfora na vida dos alunos, isto é, o esforço do aluno para realizar um curso de mestrado até sua conclusão (domínio alvo). Desse modo, os alunos, para chegarem a esse objetivo, passam por uma escada de espinhos (domínio fonte), o que demanda planejamento e disciplina (domínio alvo), pois, como a própria leitora disse mais à frente: "você tem que aprender... disciplinar... trabalhar de forma bastante disciplinada... responsável e tal e investir dinheiro... tempo, né..." (turno 90); e, continuando: "e... doutorado e... você tem uma defesa... ótimo vai tudo bem... é o tempo de esplendor que é bem fugaz... porque você tem que malhar e batalhar de novo para conseguir... parece que o tempo de esplendor da gente é bem curto..." (turno 88). Como na leitura de Maria Eduarda (excerto 4), a de Marta também foi guiada, a partir de um raciocínio inferencial de causa por efeito no que se refere à 'escada de espinhos' e 'tempo de esplendor'. Entretanto, o resultado interpretativo foi diferente, uma vez que, prosseguindo na coerência construtiva de sua leitura, ela relacionou os trechos do poema com elementos do seu contexto pessoal. Assim, concluir um doutorado, que tem como última etapa a defesa (causa) - o propósito como destino alcançado -, tem como resultado "o tempo de esplendor" (efeito), que por sua vez "é bem fugaz... porque você tem que malhar e batalhar de novo para conseguir... parece que o tempo de esplendor da gente é bem curto..." (turno 88). Embora Marta não mencione o trecho tempo de flor do poema, certamente tempo de esplendor (domínio alvo) refere-se a tempo de flor (domínio fonte), ou seja, o momento em que realizamos nossos objetivos tem uma duração tão rápida quanto a época de floração de uma planta, mas, diferente da leitura de Maria Eduarda, a leitura da professora parece enfocar que a fugacidade de um momento de realização de objetivos e seu reconhecimento não está no sujeito - que, mal realizando seus objetivos, já procura outros -, mas sim está na própria vida enquanto dilema existencial: "parece que o tempo de esplendor da gente é bem curto..." (turno 88). 


\section{Conclusão}

As leituras analisadas têm em comum a questão da investigação dos leitores quanto à personificação. Segundo Lakoff \& Turner (1989, p. 72): "Personificação nos permite usar nosso conhecimento sobre nós mesmos com um máximo de efeito, usando insights sobre nós mesmo para nos ajudar a compreender tais coisas como forças da natureza, eventos comuns, conceitos abstratos e objetos inanimados" 7 . No caso do presente poema analisado, a rosa está personificada, ou seja, houve um trabalho artístico, por parte de Cecília Meireles, no nível linguístico, das metáforas conceptuais: PESSAS SÃO PLANTAS, PROPOSITOS SÃO DESTINOS (que faz parte da metáfora A VIDA É UMA VIAGEM) e BOM É PARA CIMA. No Pensar Alto em Grupo, ao acolhermos as múltiplas leituras das metáforas em sala de aula, o leitor atua como sujeito protagonista e suas leituras são mais inferenciais e reflexivas, ao mesmo tempo em que a literatura passa a ser compreendida, sobretudo, como uma obra de arte, ou seja, como um texto que evoca um diálogo íntimo com o leitor, criando espaço para especulaçóes sobre a experiência humana e a experimentação estética.

\section{Referências}

BAKHTIN, Mikhail. Estética da criação verbal. Trad. Paulo Bezerra. 4 ed. São Paulo: Martins Fontes, 2003.

BAKHTIN, Mikhail; VOLOCHÍNOV, V.N. Marxismo e filosofia da linguagem. Problemas fundamentais do método sociológico na ciência da linguagem. Trad. Michel Lhud e Yara F. Vieira. 14.ed. São Paulo: HUCITEC, 2010.

BAYNHAM, Mike; PRINSLOO, Mastin. The future of literacy studies. Hampshire/New York: Palgrave Macmillan, 2009.

BRAIT, Beth. A natureza dialógica da linguagem: formas e graus de representação dessa dimensão constitutiva. In: FARACO, Carlos Alberto; TEZZA, Cristovão; CASTRO, Gilberto (Orgs.). Diálogos com Bakhtin. Curitiba: Editora UFPR, 2007, p. 61-80.

7 No original, em inglês: "Personification permits us to use our knowledge about ourselves to maximal effect, to use insights about ourselves to help us comprehend such things as forces of nature, common events, abstract concepts, and inanimate objects". 
CAMERON, Lynne. Metaphor in educational discourse. London: Continuum, 2003.

CHIZZOTTI, Antonio. Pesquisa em ciências humanas e sociais. São Paulo: Cortez, 2008.

ERICSSON, K. Anders; SIMON, Herbert A. Protocol Analysis. Cambridge Mass, MIT Press, 1984.

FIORIN, José Luiz. Polifonia textual e discursiva. In: BARROS, Diana Luz Pessoa; FIORIN, José Luiz (Orgs.) Dialogismo, polifonia, intertextualiade: em torno de Bakhtin. São Paulo: Editora da Universidade de São Paulo, 2011, p. 29-43.

FREIRE. Paulo. Pedagogia do oprimido. Rio de Janeiro: Paz e Terra, 1987.

JOUVE, Vincent. Por que estudar literatura? São Paulo: Parábola, 2012.

KLEIMAN, Angela. Oficina de leitura: teoria e prática. Campinas: Pontes, 2002.

LAKOFF, George; JOHNSON, Mark. Metáforas da vida cotidiana. Campinas/ São Paulo: Mercado de Letras/Educ, 2002.

LAKOFF, George; TURNER, Mark. More than cool reason: a field guide to poetic metaphor. Chicago: The University of Chicago Press, 1989.

MAGALHÂES, Izabel. Letramento, intertextualidade e prática social crítica. In: MAGALHÁES, Izabel (Org.). Discursos e práticas de letramento: pesquisa etnográfica e formação de professores. Campinas: Mercado de Letras, 2012, p. 17-68.

MASON, Jennifer. Qualitative researching. London: Sage, 1996.

MARKOVÁ, Ivana. Language and a epistemology of dialogism. In: STAMENOV, M. Language structure, discourse, and the acces to consciousness. Amsterdam/Philadelphia: John Benjamins publishing company, 1997, p. 227-250

MEIRELES, Cecilia. As palavras voam: antologia poética de Cecília Meireles. Organização: Bartolomeu de Campos de Queirós. São Paulo: Moderna, 2005.

MIZUKAMI, Maria da Graça. Ensino: as abordagens do processo. Sáo Paulo: EPU, 1986.

MOITA LOPES, Luiz Paulo. Introdução - uma linguística aplicada mestiça e ideológica: interrogando o campo do linguista aplicado. In: MOITA LOPES, Luiz Paulo (Org.). Por uma linguistica aplicada indisciplinar. São Paulo: Parábola, 2006, p. 13-44. 
PONTECORVO, Clotilde. Discutindo se aprende: interação social, conhecimento e escola. Trad. Cláudia Bressan e Susana Termignoni. Porto Alegre: Artmed, 2005.

STREET, Brian. Literacy in theory and practice. Cambridge: Cambridge University Press, 1984.

ZANOTTO, Mara Sophia. O processo de compreensão da metáfora na formação dos professores de língua materna. In: ZANOTTO, Mara Sophia; CELANI, Maria Antonieta Alba (Orgs.). Linguística aplicada: da aplicação da linguística à linguística transdisciplinar. São Paulo, Educ, 1992, p. 233-246.

. Metáfora, cognição e ensino de leitura. D.E.L.T.A., v. 11, n. 2, p. 241-254, São Paulo, 1995.

ZANOTTO, Mara Sophia; PALMA, Dieli Vesaro. Metáfora, cognição e ensino de leitura: o pensar metafórico em sala de aula. In: BASTOS, N.B. (Org.). Lingua portuguesa: história, perspectivas, ensino. São Paulo: Educ, 1998, p. 167-180.

ZANOTTO, Mara Sophia et al. Apresentação à edição brasileira. In: LAKOFF, George; JOHNSON, Mark. Metáforas da vida cotidiana. Campinas: Mercado de Letras, 2002. p. 9-37.

ZANOTTO, Mara Sophia. Modelos culturais e indeterminação metafórica. Organon, n. 43, p. 97-118, Porto Alegre, 2007.

. The multiple of 'metaphor' in the classroom co-construction of inferential chains. D.E.L.T.A., São Paulo, v. 26, p. 615-644, 2010.

- Particularidades da metáfora em poemas e implicaçóes para o seu processo de compreensão. In: Intercâmbio de Pesquisas em Linguística Aplicada, 18, 2011, São Paulo. Anais... São Paulo: PUC-SP, 2011, p.1-46.

. A construção de uma prática de letramento para o ensino e pesquisa de leitura da 'metáfora' em textos literários. In: LIMA, Aldo (Org.). A propósito da metáfora. Recife: Editora UFPE/CatédraUnesco de Leitura-PUC/Rio, 2014a, p. 193-241

- As múltiplas leituras da metáfora: desenhando uma metodologia de investigação. Signo, v. 39, n. 67, p. 3-17, Santa Cruz do Sul, 2014 b. 


\title{
THE MULTIPLE READINGS OF METAPHORS IN LITERARY TEXTS: A CONTRIBUTION TO THE DEVELOPMENT OF A MORE REFLECTIVE AND PROTAGONIST READER
}

\begin{abstract}
Aiming at developing a more reflective and protagonist literary reader, this paper analyzes the multiple readings of the metaphor in the poem "Rosa", by Cecília Meireles, which were generated during dialogic and collaborative Group Think-Aloud practice, through coconstruction and negotiation of meaning. This study investigates how the conceptual metaphor participated in the process of the readers understanding of the poetic metaphor.
\end{abstract}

KEYWORDS: literary literacy; The Group ThinkAloud; metaphor.

Recebido em: 20/10/2015

Aprovado em: 02/03/2016 